\title{
DESINFECÇÃo DE EFLUENTES COM TRATAMENTO TERCIÁRIO UTILIZANDO ENERGIA SOLAR (SODIS): AVALIAÇÃO DO USO DO DISPOSITIVO PARA CONCENTRAÇÃO DOS RAIOS SOLARES
}

\author{
DISINFECTION OF EFFLUENT OF WASTEWATER TREATED USING SOLAR \\ ENERGY (SODIS): EVALUATION OF A SOLAR CONCENTRATOR DEVICE
}

\section{JOSÉ EUCLIDES STIPP PATERNIANI}

Doutor em Hidráulica e Saneamento EESC/USP. Professor do Departamento de Saneamento e Ambiente da FEC/UNICAMP

MARCELO JACOMINI MOREIRA DA SILVA

Mestre em Saneamento e Ambiente FEC/UNICAMP. Doutorando em Saneamento e Ambiente FEC/UNICAMP

Recebido: 18/05/04 Aceito: 28/01/05

\section{RESUMO}

A energia solar, além de ser uma fonte natural disponível, é perfeitamente aplicável para desinfecção de águas em regiōes menos favorecidas em infra-estrutura e recursos financeiros, uma vez que não há necessidade da dosagem de produtos químicos e não há custo já que materiais comerciais descartados podem ser reutilizados. O presente trabalho utilizou garrafas PET transparentes com a metade pintada de preto, sendo consideradas como variáveis do processo de desinfecção por ação da luz solar: tempos de exposição 1, 2, 4 e 6 horas e o uso de um concentrador de raios solares. Os parâmetros de controle do processo de desinfecção foram turbidez, cor aparente, temperatura, coliformes totais e E. coli, sendo os três últimos parâmetros avaliados antes e após o processo. Para a avaliação de reativação bacteriana a água foi armazenada em moringas de mesa por 24 horas, simulando uma situação comum nas residências rurais brasileiras. Os resultados mostraram que o uso do concentrador solar permite reduzir o tempo de exposição ao sol de 6 para 4 horas, sem prejuízo da eficiência do SODIS. Sendo utilizado o concentrador solar com tempo de exposição de 6 horas tem-se, além do processo de desinfecção, o processo de pasteurização solar (SOPAS), permitindo assim a utilização deste para potabilização da água. Também foi observado que a presença de nuvens reduz a incidência de radiação solar e, portanto, a eficiência do SODIS. Esta última ocorre mesmo com a água atingindo temperatura mais elevada durante a desinfecção.

PALAVRAS-CHAVE: Tratamento de água, qualidade da água, alternativas tecnológicas, saneamento rural.

\section{ABSTRACT}

Besides being an available natural resource, the solar energy is very applicable in places with few recourses and low money resources, because there aren't either the need of chemical products neither a huge cost (commercial materials can be reused). To make this job we re-used PET bottles half painted black with the variables: 1, 2, 4 and 6 hours of heat exposion and we also used a concentrator of rays of sunshine. The affluent control parameters were turbidity, apparent color, temperature, total coliforms and E. coli. These last three were evaluated before and after the desinfection process (effluent parameters). To assess the bacteria reactivation we kept the water in bottles for 24 hours, pretending a very common situation in Brazilian rural houses. We conclude that the use of the concentrator of rays of sunshine can reduce the heat exposion from 6 to 4 hours, without harm the SODIS efficience. Using the concentrator of rays of sunshine for 6 hours we can obtain, besides SODIS, the process of solar pasteurization (SOPAS), which stops the re-growth of bacteria with a $70^{\circ} \mathrm{C}$ water temperature. We also observed that when the sky is cloudy the incidention of solar radiation and, therefore, the SODIS efficience decrease, even if the water temperature is higher during the desinfection. Although, this factor doesn't mean a significative influence statistically.

KEYWORDS: Water treatment, water quality, technological alternatives, rural sanitation.

\section{INTRODUÇÃO}

O uso da energia solar para desinfecção de águas (SODIS) vem sendo proposto para utilização, por exemplo, nas áreas rurais de países em desenvolvimento, possibilitando a desinfecção de águas captadas em poços ou mananciais superficiais, cujas características físicas e químicas são adequadas ao consumo humano, mas sanitariamente duvidosas, uma vez que apenas a avaliação do aspecto dessas, não permite conclusão sobre a contaminação da amostra de água coletada.

Assim, o presente trabalho realizou um estudo sobre a inativação de coliformes totais e $E$. Col $i$, através da desinfecção com energia solar de águas residuárias efluentes do tratamento terciário em leitos cultivados e do recrescimento dos mesmos após o acondicionamento desta em condiçôes similares às que são utilizadas para armazenar água potável em habitações localizadas no meio rural.

O uso do efluente dos leitos cultivados deve-se, apenas, a alta concentração de coliformes totais e E. Coli. Assim, foi possível avaliar a desinfecção solar (SODIS) e do concentrador solar em con- 
dições onde a água possui elevada contaminação biológica.

\section{MATERIAL E MÉTODOS}

\section{Características do local e das condições de realização do experimento}

A instalação piloto para a investigação experimental foi montada no Campo Experimental da Faculdade de Engenharia Agrícola da UNICAMP, localizado no município de Campinas (Latitude $\left.22^{0} 49^{\prime} 05^{\prime \prime} \mathrm{Sul}\right)$.

As avaliaçôes do sistema SODIS foram realizadas variando os parâmetros de tempo de exposição das garrafas ao sol (1, 2, 4 e 6 horas), cobrindo assim os pontos de intervalos de tempo entre 40 minutos e 6 horas, recomendados pela literatura para inativação completa de coliformes, conforme cita Sommer et al (1997) e Wegelin et al (1994); de condições climáticas, com a escolha de dias com céu totalmente aberto e dias com o céu parcialmente encoberto por nuvens; e com a utilização de um concentrador solar semelhante ao proposto pelo IMTA - Instituto Mexicano de Tecnologia da Água (Herrera, 2003), construído com madeiras e recoberto com folhas de papel alumínio, para aumentar a eficiência do SODIS.

A temperatura do ar e a intensidade de radiação solar total foram medidas na estação meteorológica do CEPAGRI Centro de Ensino e Pesquisa em Agricultura.

A avaliação da concentração da população de coliformes totais e E. Coli foi feita por meio da técnica do substrato cromogênico.

\section{Materiais utilizados}

Reutilizaram-se vasilhames PET descartados após o consumo de refrigerantes, sendo escolhidos os incolores. A metade do vasilhame voltada para baixo foi lixada e pintada com tinta esmalte na cor preto fosco.

O concentrador solar proposto pelo IMTA-Instituto Mexicano de Tecnologia da Agua, possui capacidade para apenas três garrafas, sendo construído com uma base e quatro aletas revestidas com papel alumínio. Para garantir que os quatro tempos de exposição adotados estivessem sob as mesmas condições foi construído um concentrador solar com as mesmas características geométricas, alterando apenas as medidas da base e de duas aletas, para que fossem utilizadas quatro garrafas ao invés de três, como mostra a Figura 1.

\section{Condução do experimento}

A água utilizada foi efluente doméstico com tratamento terciário, que apresentou características adequadas à utilização do processo de desinfecção solar, tendo turbidez média de 5,52NTU, cor aparente média de 125,67 [Pt-Co] e concentrações de coliformes totais e E. Coli da ordem $10^{5}$ e $10^{4} \mathrm{NMP}(100 \mathrm{ml})^{-1}$, respectivamente. A Figura 2 mostra o experimento em andamento.

Para a avaliação do recrescimento bacteriano, uma vez que o SODIS não possui efeito residual, a água desinfetada foi transferida para moringas de mesa, de material cerâmico, com volume de 1 litro, e armazenada por 24 horas em condiçōes naturais, simulando as condições de armazenamento doméstico e, então, analisadas as concentrações de coliformes totais e E. Coli.
A Figura 3 mostra as moringas onde a água ficou armazenada após o processo de desinfecção.

O recrescimento bacteriano foi avaliado pela razão entre o número de indivíduos vivos 24 horas após a desinfecção e no momento da retirada das garrafas do sol.

\section{RESULTADOS E DISCUSSỐES}

\section{Dados experimentais}

As condiçōes experimentais, referentes ao clima, foram determinadas pela ocorrência de nuvens no céu e estão mostradas nas Figuras 4 a 7 .

Os dados experimentais dos dias com o céu sem nuvens apresentaram menor variabilidade de intensidade de radiação solar, mostrando um comportamento climático semelhante às informaçôes encontradas na literatura técnica e divulgadas por SODIS (2003) ilustradas na Figura 8, que justifica tal variabilida-

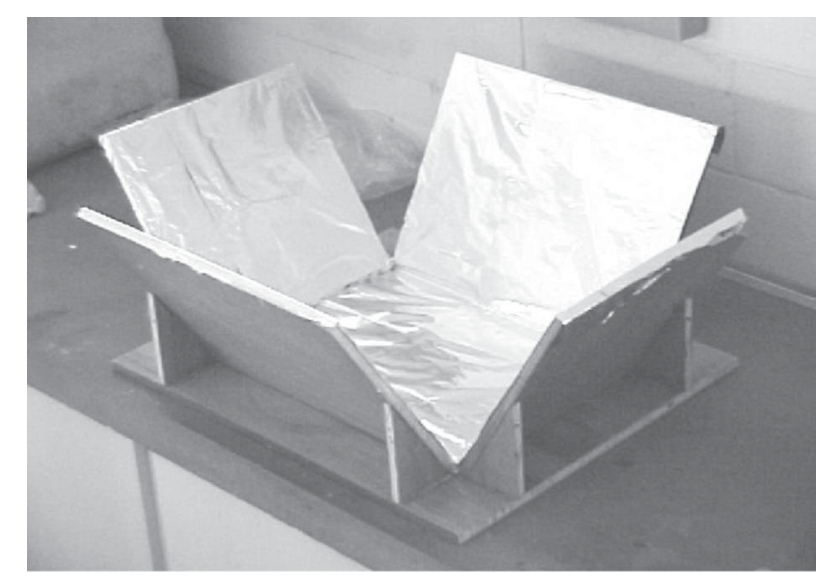

Figura I - Concentrador solar montado com revestimento de papel alumínio

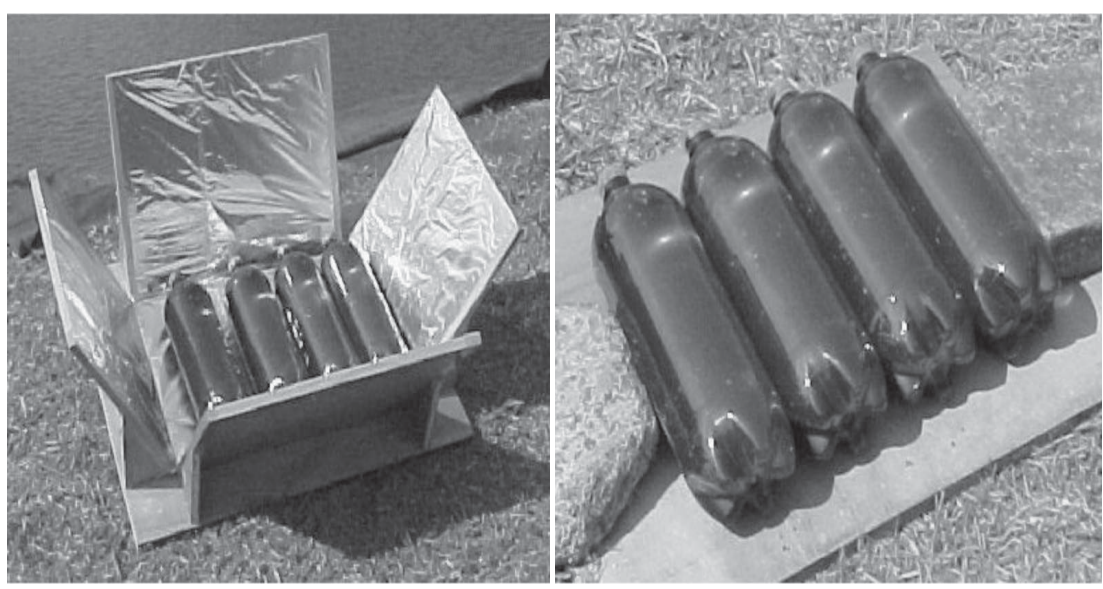

Figura 2 - Experimento em andamento: garrafas expostas ao sol com e sem a utilização do concentrador dos raios solares 

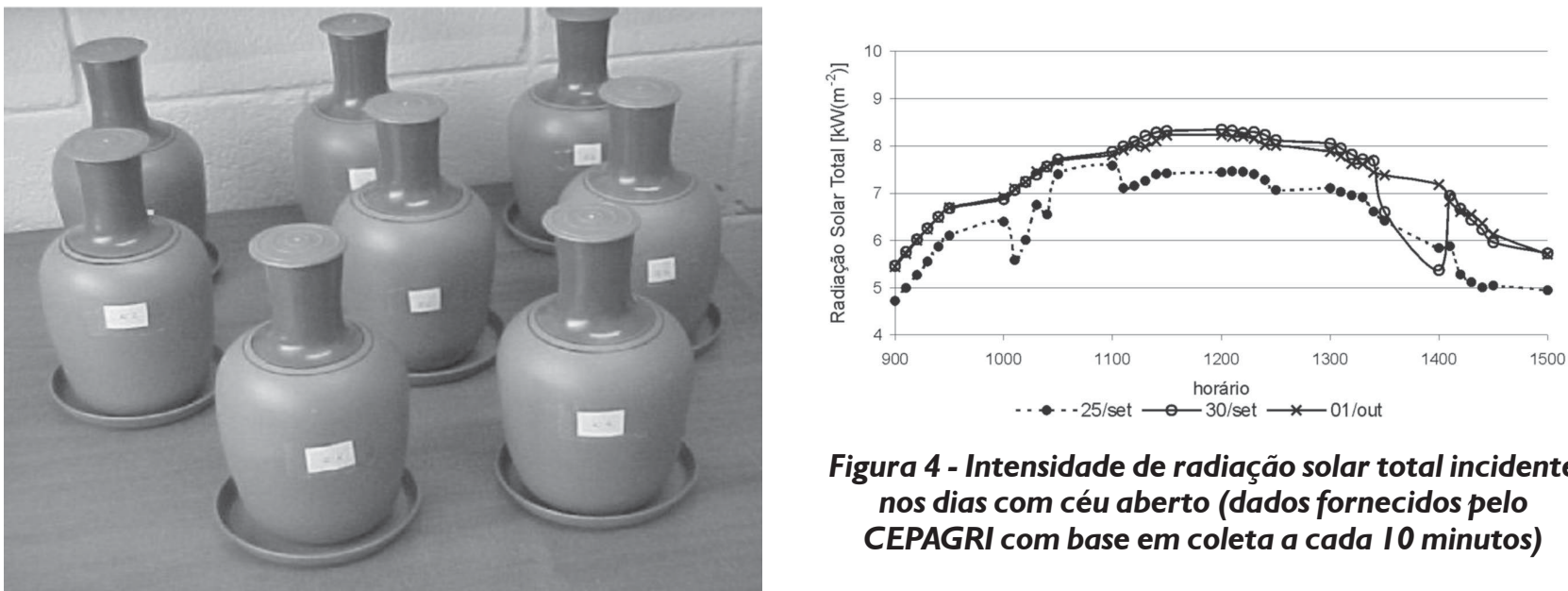

Figura 4 - Intensidade de radiação solar total incidente nos dias com céu aberto (dados fornecidos pelo CEPAGRI com base em coleta a cada 10 minutos)

Figura 3 - Moringas para armazenagem de água, simulando uma situação comum no meio rural

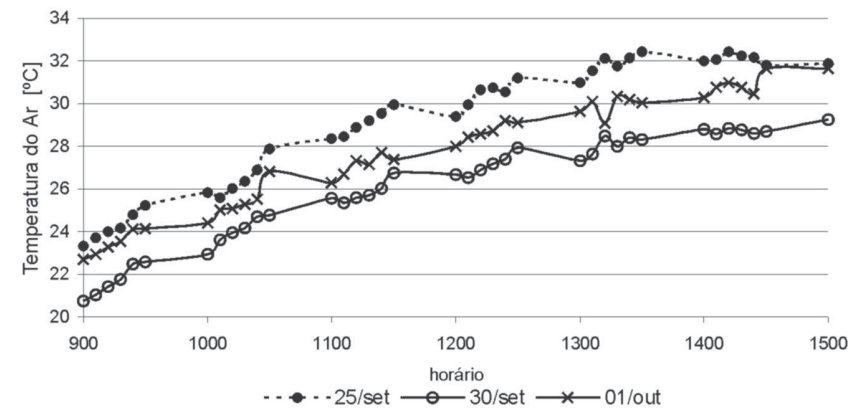

Figura 5 - Temperatura do ar nos dias com céu aberto (dados fornecidos pelo CEPAGRI com base em coleta a cada 10 minutos)

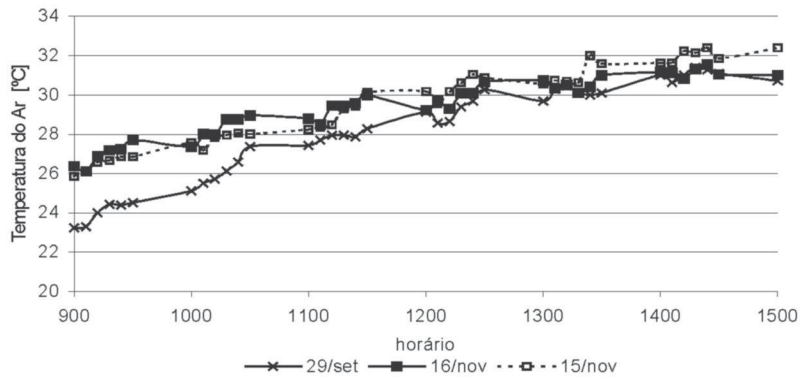

Figura 6 - Intensidade de radiação solar total íncidente nos dias em que havia nuvens no céu (dados fornecidos pelo CEPAGRI com base em coleta a cada $(0$ minutos) de pela interceptação momentânea dos raios solares pelas nuvens.

\section{Influência do concentrador solar na eficiência do SODIS}

A eficiência do SODIS, segundo revisão bibliográfica, está diretamente relacionada com a temperatura da água e com a presença de radiação solar, sendo recomendado o mínimo de $50^{\circ} \mathrm{C}$ e tempo de exposição de 6 horas; com o uso do concentrador solar a taxa de aquecimento da água é aumentada, como mostra a Figura 9.

Nota-se que o concentrador atua mais significativamente no aumento da temperatura, tendo esta um comportamento logarítmico com alto coeficiente de correlação, $\mathrm{R}^{2}=0,9534$ utilizando o concentrador solar e $\mathrm{R}^{2}=0,9701$ no processo de desinfecção tradicional.

A eficiência de inativação de coliformes totais nas garrafas que não utilizaram o concentrador solar atingiu a

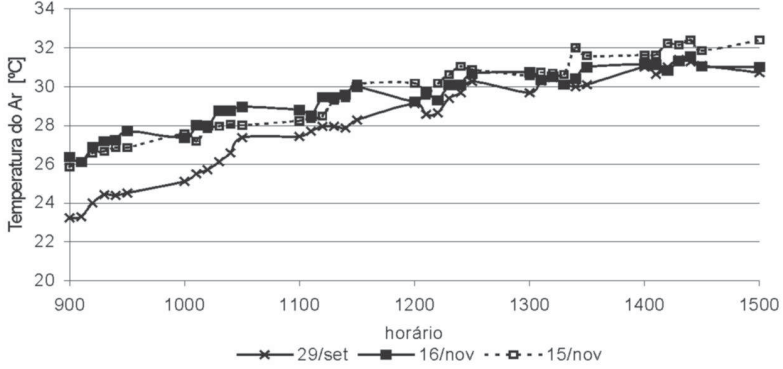

Figura 7 - Temperatura do ar nos dias em que havia nuvens no céu (dados fornecidos pelo CEPAGRI com base em coleta a cada 10 minutos)

média de 99,56\% (valor residual médio 61,6 NMP/100ml) com tempo de exposição de 6 horas; enquanto a eficiência para garrafas com o concentrador solar foi em média 99,89\% (valor residual médio $15,4 \mathrm{NMP} / 100 \mathrm{ml}$ ) e 99,98\% (valor residual médio $14 \mathrm{NMP} / 100 \mathrm{ml}$ ) com 4 horas e 6 horas de exposição, respectivamente.

Observou-se, também, que as garrafas cujas temperaturas alcançaram $50^{\circ} \mathrm{C}$ e tempo de exposição de 6 horas, sem o concentrador solar, tiveram 100\% de eficiência, confirmando os dados de pré-requisitos encontrados por Wegelin (1994) e Sommer et al (1997). Já naquelas que utilizaram o concentrador solar a eficiência foi de $100 \%$ com 4 horas de exposição, quando alcançou-se a temperatura de $70^{\circ} \mathrm{C}$.

A inativação de E. Coli foi em média 99,56\% (valor residual médio 


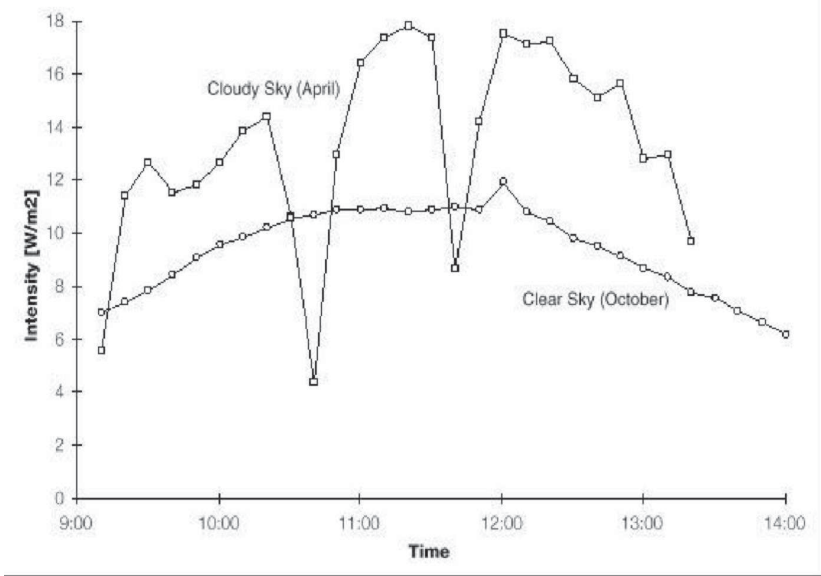

Figura 8 - Variação diária da intensidade de radiação solar UV-A em duas épocas diferentes do ano na região de Beirute - Libano (SODIS, 2003)

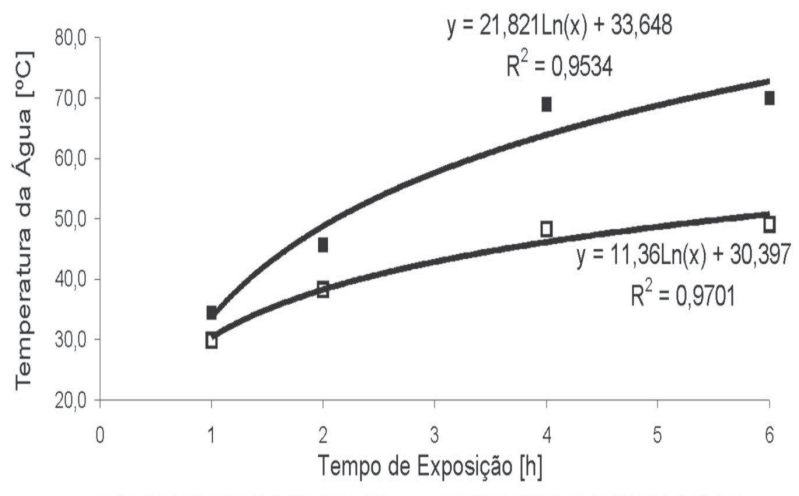

口SEM CONCENTRADOR SOLAR - COM CONCENTRADOR SOLAR

Figura 9 - Temperatura média da água no processo de desinfecção solar (SODIS)
61,6 NMP/100ml) nas garrafas que não utilizaram o concentrador solar com tempo de exposição de 6 horas; enquanto a eficiência do sistema com o concentrador foi 100\% com apenas 4 horas de exposição.

O desenvolvimento do processo de desinfecção ao longo do tempo de exposição em função do uso do concentrador solar é mostrado na Figura10, sendo observado que a eficiência é elevada para tempos de exposição maiores que 4 horas.

\section{Influência das condições climáticas na eficiência do SODIS}

O aquecimento da água e a inativação bacteriana tiveram influência na condição climática presente durante o tempo de exposição ao sol, sendo que a temperatura da água durante o processo (Figura 11) foi superior nos dias sem nuvens.

A inativação média de bactérias do grupo coliformes totais foi 3,29\% maior no processo realizado com céu aberto para o tempo de exposição de 4 horas. Para o tempo de exposição de 6 horas a diferença na eficiência diminuiu, chegando à eficiência de 99,992\% (valor residual médio 1,1 NMP/100ml) nos dias com céu aberto e 99,6\% (valor residual médio $56 \mathrm{NMP} / 100 \mathrm{ml}$ ) nos dias com nuvens, diferença de apenas $0,392 \%$.

De modo análogo, a diferença de eficiência de inativação de E. Coli foi $100 \%$ nos dias com céu aberto e $98 \%$ nos dias com nuvens, tanto para 4 horas como com 6 horas de exposição ao sol.

A Figura 12 representa o desenvolvimento da desinfecção ao longo do tempo de exposição em função das condições climáticas.

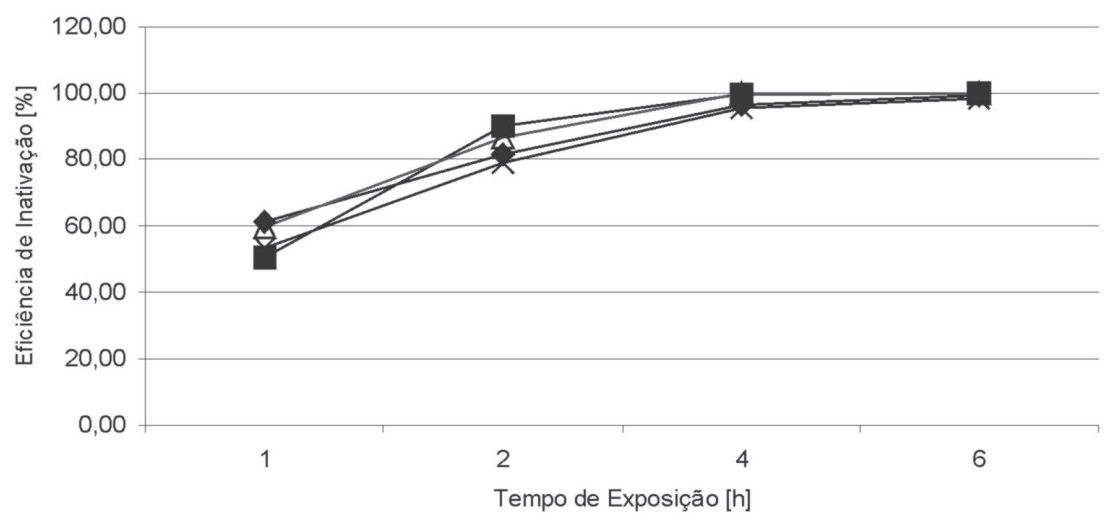

$\begin{array}{ll}\longrightarrow \text { - coliformes totais sem concentrador solar } \rightarrow-\text { coliformes totais com concentrador solar } \\ \triangle \text { E.Coli com concentrador solar } & - \text { E.Coli sem concentrador solar }\end{array}$

Figura 10 - Eficiência de Inativação do SODIS em função do uso do concetrador solar

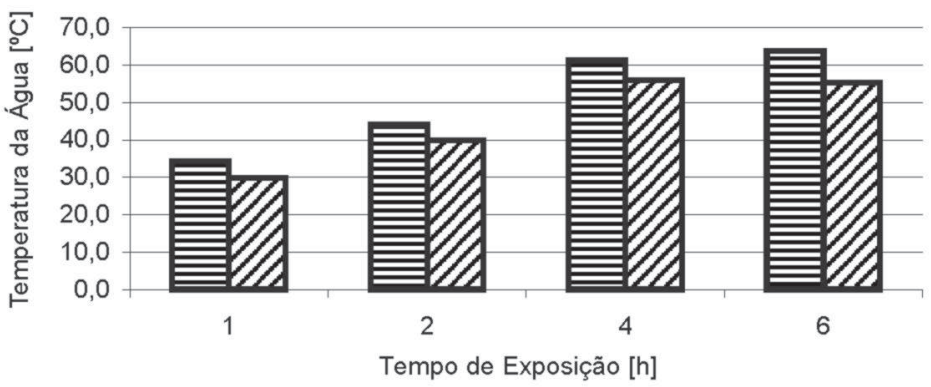

EAberto $\boldsymbol{Z}$ Nuvens

Figura I I - Temperatura média da água durante o processo de desinfecção solar 


\section{Recrescimento bacteriano}

A inibição do recrescimento bacteriano tem um papel importante devido à manutenção da potabilidade da água e, 24 horas após o término da exposição ao sol, foram obtidos valores de concentração de coliformes totais e E. Coli tanto superiores como inferiores àqueles apresentados no momento final do SODIS, indicando que existe a possibilidade de ocorrer um recrescimento de microrganismos após o processo SODIS.

Com o uso do concentrador de raios solares, proposto pelo IMTA, independente da condição climática, a temperatura média alcançada foi da ordem de $70^{\circ} \mathrm{C}$ com 4 horas de exposição, não havendo o recrescimento de bactérias do grupo coliformes totais nem E.Coli. Nessas condições, segundo Sommer et al (1997), tem-se um processo de pasteurização solar (SOPAS) e não de desinfecção solar, mostrando que o dispositivo proposto permite o uso desse processo de desinfecção para produção de água potável.

O recrescimento bacteriano depende significativamente da temperatura que a água alcançou durante a desinfecção. A Figura 13 mostra o recrescimento bacteriano em função da temperatura da água, onde se nota que o recrescimento foi inibido totalmente apenas nas amostras cuja temperatura da água esteve em torno de $70^{\circ} \mathrm{C}$ no final do período de exposição ao sol.

\section{CONCLUSÕES}

O uso do concentrador solar proposto pelo IMTA permite reduzir o tempo de exposição ao sol de 6 horas para 4 horas, sem prejuízo da eficiência do SODIS.

A presença de nuvens reduz a incidência de radiação solar, bem como a eficiência do SODIS, mesmo com a temperatura da água mais elevada durante a desinfecção.

O SODIS não possui efeito residual, o que favorece o recrescimento bacteriano 24 horas após o término do processo de desinfecção quando a temperatura da água ficou abaixo de $50^{\circ} \mathrm{C}$;

$\mathrm{O}$ uso do concentrador solar aqueceu a água até $70^{\circ} \mathrm{C}$, promovendo uma pasteurização solar (SOPAS) que inativou $100 \%$ das bactérias;

$\mathrm{O}$ uso do concentrador solar inibiu o recrescimento de bactérias após 24 horas do término do processo para amostras cuja água foi aquecida até $70^{\circ} \mathrm{C}$ por, pelo menos, 4 horas.
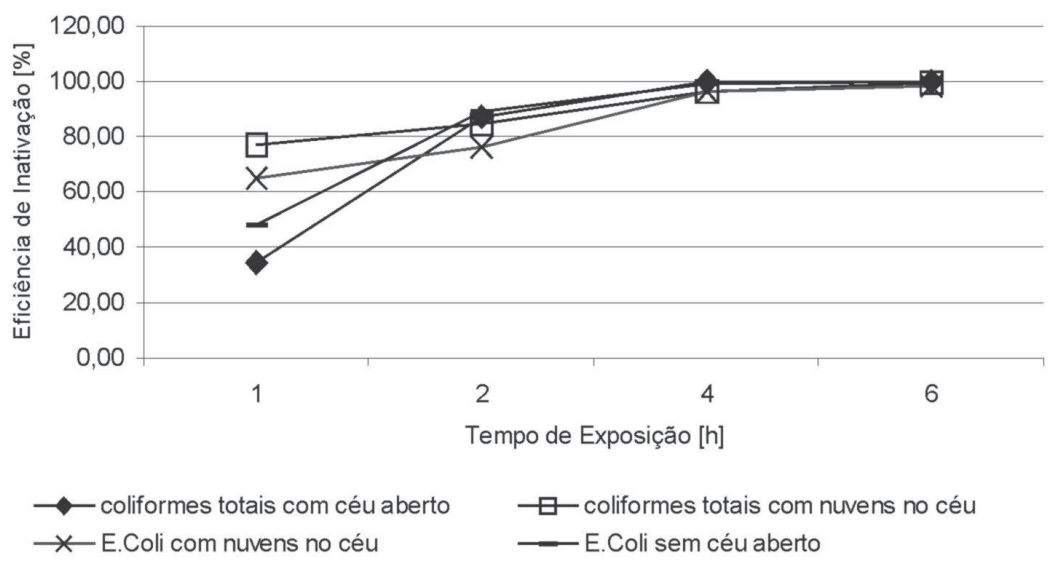

Figura I 2 - Eficiência de Inativação do SODIS em função da condição climática

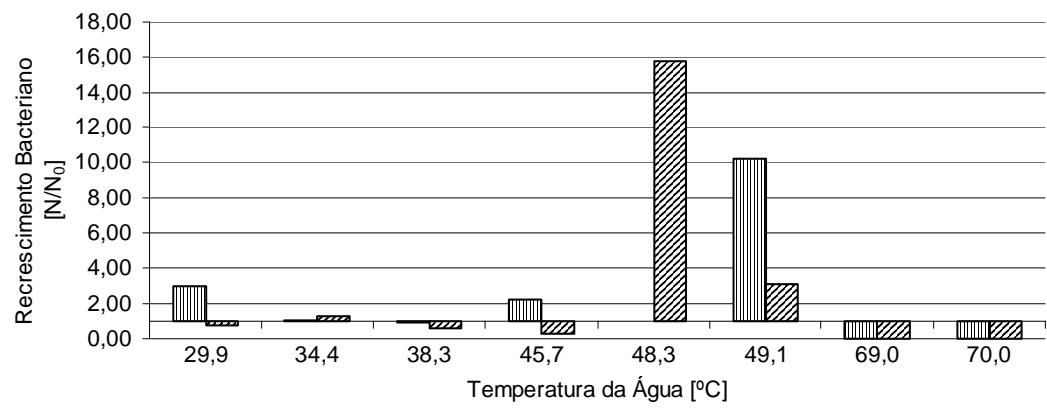

m Coliformes Totais

E.Coli

\section{Figura I 3 - Recrescimento de Bactérias em função da Temperatura da Água (valores médios)}

Com o uso do concentrador solar é possível utilizar-se o processo de desinfecção solar para potbilização da água.

\section{AGRADECIMENTOS}

À FEC/UNICAMP, pela participação no programa de pós-graduação; ao CNPQ, pelo apoio financeiro durante o desenvolvimento deste trabalho; e ao CEPAGRI - Centro de Ensino e Pesquisa em Agricultura, pelo fornecimento dos dados climáticos.

\section{REFERÊNCIAS}

HERRera, A. G. Desinfección Solar Del Agua, IMTA - Instituto Mexicano de Tecnologia del Água, Mexico, 2003

SODIS. Climatic Conditions: Seasonal Effects and Weather Changes, Technical Note \#6, http:// www.sodis.ch, março de 2003

SODIS. Concentrador solar IMTA: Files, http:// www.sodis.ch/files_e-conference, março de 2003

SOMMER, B., et al. Sodis - An Emerging Water Treatment Process, Journal of Water Suply:
Research and Technology - Aqua, v. 46, n3, p. 127 - 137, 1997

WEGELIN, M., et al. Solar Water Disinfection: Scope on Process and Analysis of Radiation Experiments, Journal of Water Suply: Research and Technology - Aqua, v. 43, n3, p. $154-$ 169, 1994

Endereço para correspondência:

José Euclides Stipp Paterniani Departamento de Saneamento e Ambiente FEC/UNICAMP Cidade Universitária Zeferino Vaz, Barão Geraldo I3083-970 Campinas - SP - Brasil Tel: (19) 3788-1019 E-mail: pater@agr.unicamp.br 